\title{
LEARNING TECHNOLOGY STANDARDIZATION IN EUROPE
}

Implications in electronic design

Frans Van Assche

European Schoolnet.E-mail: frans.van.assche@eun.org

Abstract: Learning Technology Standardization in Europe addresses some specific issues which are complementary to worldwide standardization activities.

Key words: E-learning systems; Learning Technology; Standardization; Europe

\section{INTRODUCTION}

E-Learning has many aspects including learning related, content related, data and metadata, infrastructure, systems and environments, administration, teacher and student communities. Each of these aspects is subject to standardization one way or another and the effective and efficient operation of any educational system is greatly affected by the degree of interoperability reached. Indeed interoperability is an enabler for sharing pedagogy, infrastructures, tools and resources (digital and non-digital including human resources). It has been well documented that interoperability and the use of standards has a number of benefits in terms of lower costs, greater supply, higher accessibility and availability, higher quality, and a shorter delivery time. However, sharing of data, content, tools and services can only be achieved when clear technical agreements are made between all parties concerned. The more global this agreement is, the greater the benefit. In this respect, Europe standardization and pre-standardization efforts seek adoption of European work at the global level and vice-versa. Because of its multicultural and multilingual nature, Europe puts great 
emphasis on internationalization and localization of standards and specifications.

\section{STANDARDIZATION BODIES AND CONSORTIA}

The European standardization body is CEN/ISSS. In addition Europe has a number of standardization consortia and organizations which represent European user communities. The most important ones are presented in section 2.2.

\subsection{CEN/ISSS}

The European standardization body, also in the field of education, is CEN/ISSS. CEN stands for 'Commité Européen de Normalisation' or the European Committee for Standardization. CEN was founded in 1961 by the national standards bodies in the European Economic Community and EFTA countries.

Today CEN is contributing to the objectives of the European Union and European Economic Area with voluntary technical standards which promote free trade, the safety of workers and consumers, interoperability of networks, environmental protection, exploitation of research and development programmes, and public procurement. CEN/ISSS is important because it is an accredited standardisation body. This means that its members, currently 28 European Countries are legally obliged to implement the standards issued by CEN/ISSS. In the field of e-learning, there are two workshops (i.e. working groups): the Workshop on Learning Technologies and the Workshop on ICT Skills and Profiles.

The Workshop on Learning Technologies (WSLT) was established in February 1999. Its objective is to encourage the effective development and use of relevant and appropriate standards for learning technologies for Europe.

The WSLT decided, as a matter of principle, not to duplicate work already being done elsewhere, but to ensure that diverse European requirements are properly addressed by global initiatives. Specifications, agreements, guidelines or recommendations are developed when no initiative addressing the identified requirements is in place yet or when global solutions developed elsewhere need to be localized to European requirements.

Finally, in the domain of eLearning and eTraining, considerable efforts are invested under the IST programme of the European Commission as well as via many national or European initiatives. Projects producing 
specifications, architectures, reference models, etc., with the intention of attracting broader support and recognition of their work, can use the Workshop as a useful tool for reaching a European-wide consensus on their deliverables.

The Workshop on ICT Skills and Profiles was established in April 2003 and addresses initially two subject areas:

For IT practitioners' profiles at professional level the objectives are:

- Validate the skill/competence profiles developed so far by the Career Space (Industry) Consortium

- Recommend respective industry standards for skills and competencies profiles

- Encourage the effective use and wider application of the respective professional and occupational profiles for IT practitioners as standards for employment and careers in Europe

For curriculum development guidelines for Higher Education Providers the objective is to validate the curricula development profiles developed so far by the Career Space (Industry) Consortium.

\subsection{Other European standardization players}

First of all there are the national standardization bodies such as DIN (Germany), AFNOR (France), BSI (UK), UNI (Italy). They organize standardization activities is different ways. They often organize standardization in conjunction with e-government. Other countries would look at e-standards as a whole while some would have different standardization structures for dealing with standards in education. For example in the UK, CETIS deals with Higher and Further Education, while other institutions will deal with vocational training, schools, etc. Countries may choose to have a representation at the standardization bodies ISO and/or CEN/ISSS.

The ARIADNE (Alliance of Remote Instructional Authoring and Distribution Networks for Europe) Foundation for the European Knowledge Pool was created to exploit and further develop the results of the ARIADNE and ARIADNE II European Projects, which created tools and methodologies for producing, managing and reusing computer-based pedagogical elements and telematics supported training curricula. Together with the IMS Global consortium it is at the basis of the Learning Object Metadata standards issued by IEEE. Validation of the tools and concepts took place in various academic and corporate sites across Europe and was encouraging enough to go ahead with this idea of non-commercial exploitation.

European Schoolnet (EUN) is an international partnership of 26 European Ministries of Education developing learning for schools, teachers 
and pupils across Europe. EUN provides insight into educational use of ICT (information and communications technology) in Europe for policy-makers and education professionals. EUN is actively involved in the work of CEN/ISSS WSLT, IMS Global consortium, IMS Europe, and the Schools Interoperability Framework. The EUN has organized its standardization work in an international action on the Learning Interoperability Framework for Europe (LIFE).

The eLearning Industry Group, eLIG, is an open consortium of leading ICT (information and communications technology) companies and eLearning content providers who seek to promote eLearning throughout Europe, in schools, universities, the workplace and homes. The eLearning Industry Group was launched on 25 April 2002. ELIG has a project group on Open Standards. Its objective is to encourage the adoption of and participation in the development of open technical standards for eLearning, so that international open standards, together with technological innovation and free market competition will deliver solutions that encourage broad participation in eLearning.

Recently, European IMS, was incorporated in the Netherlands as a separate non-profit organisation. European IMS is an offshoot of the IMS Global consortium and seeks to ensure participation and use by Europe in open specifications, support adoption of specifications by European vendors, promote an inclusive, open, accessible, European and Global elearning market (i.e. "level the playing field"), and promote the development of open source libraries to foster implementation and innovation.

The European Commission is last but not least an important player in the field of standardisation. The European Commission is organised in different directorates which each have a specific emphasis and strategy for supporting standardisation work. For example, the Directorate for industry supports the standardisation work through direct funding of work items proposed by CEN/ISSS; the Directorate for Information Society Technologies requires for research projects to explicitly describe the contribution to national or international standards; the Directorate for Education and Culture stimulates the contribution and adoption by the user communities.

\section{STANDARDIZATION ACTIVITIES IN EUROPE}

The European organizations dealing with standardization, prestandardization, and adoption of standards and specifications are active in a number of areas related to learning resources, learning management, learning communities, and institutional administration. In addition some standards and specifications address issues across these areas. The activities 
are too numerous to be elaborated in the context of this paper and the ones listed are merely examples of the work being carried out.

In the area of learning resources we find the only standard in the field of education, the IEEE Standard for Learning Object Metadata (LOM). Apart from delivering the basis for this standard through the ARIADNE project, Europe contributes in this area, through work on internationalization and localization (including translation) of the LOM, multi-linguality aspects, the relationship to national curriculums, copy-rights and digital rights, and more adoption issues in general. Furthermore, much work has been done on a more comprehensive model for education resulting in various educational modeling languages which eventual find their way in specifications such as IMS learning design.

The field of learning management addresses issues such as student information, student progress, the learner information package, gradebooks, etc. In short everything necessary to manage the learning process. In this area European institutions contribute by activities such as providing a European Model for Learner Competencies, elaborating the concept of an ePortfolio, and elaborating a method of recording the training carried out and skills acquired during a period of work experience, undertaken as part of an on-going training programme, in another European country (EuroPass).

Apart from resources and learning management, the field of education requires substantial support in establishing different communities. This encompasses communication and collaboration tools for learning, authoring material, exchanging technical expertise. In this area one can build upon quite a number of existing standards and specifications ranging from vCard to the whole IMS enterprise specifications. However very little work has been done on harnessing existing technologies and standards for the benefit of the education community.

A prominent institution administration specification is the School Interoperability Framework (SIF). SIF is an initiative of North-American industry. In Europe a European version of the SIF has been elaborated in the OASIS project which was reviewed by CEN/ISSS. The CEN/ISSS WSLT reviewed the SIF Infrastructure, Architecture, Message Processing Layer, the Transport Layer, the SIF Data model, and elaborated internationalisation and harmonisation recommendations.

Apart from the four areas above, Europe addresses a number of topics that support those areas including work on application profiling, harmonization of vocabularies, quality issues with respect to all processes related to education, accessibility to resources and software tools, interoperability and brokerage of resources and services. Many of these activities happen in close collaboration with international standards bodies and consortia. 